\title{
Manoel Bomfim e Celso Furtado: pensadores originais do
}

Brasil

\section{Manoel Bomfim and Celso Furtado: original thinkers of Brazil}

\author{
Wilson Vieira \\ Instituto de Economia (IE), Universidade Federal do Rio de Janeiro (UFRJ). \\ vieiraeco@gmail.com \\ orcid.org/0000-0002-4734-0366
}

\section{Leila Almeida Barbosa}

Programa de Pós-Graduação em História das Ciências e das Técnicas e Epistemologia (HCTE), Universidade Federal do Rio de Janeiro (UFRJ).

\section{leilaalmeidabarbosa@yahoo.com.br \\ orcid.org/0000-0002-2606-8578}

Resumo. O objeto deste trabalho é a análise da originalidade das reflexões de Manoel Bomfim (1868-1932) e Celso Furtado (1920-2004) para pensar o Brasil. Os objetivos são: i) apresentar a originalidade de cada um dos autores nas suas reflexões sobre o Brasil; ii) mostrar que a reflexão desses teóricos faz parte de um pensamento fundador brasileiro e autóctone, original. A hipótese de trabalho é a de que esses teóricos fazem parte do grupo de pensadores brasileiros que fundam um pensamento original, autóctone no Brasil a partir do início do século XX.

Palavras-chave: Celso Furtado. Manoel Bomfim. Pensamento político-socialeconômico brasileiro.

Abstract. The object of this work is the analysis of the originality of Manoel Bomfim's (1868-1932) and Celso Furtado's (1920-2004) reflections to think about Brazil. The objectives are: i) to present the originality of the authors in their reflections about Brazil; ii) to show that the reflection of these theorists is part of an original Brazilian founding thought. The working hypothesis is that these theorists are part of the group of Brazilian thinkers founders of an original and autochthonous thought in Brazil from the beginning of the 20th century

Keywords: Celso Furtado. Manoel Bomfim. Brazilian political-social-economic thought. 


\section{Introdução}

O objeto deste trabalho é a análise da originalidade das reflexões de Manoel Bomfim (1868-1932) e Celso Furtado (1920-2004) para pensar o Brasil. Os objetivos são: i) apresentar a originalidade de cada um dos autores nas suas reflexões sobre o Brasil; ii) mostrar que a reflexão desses teóricos faz parte de um pensamento fundador brasileiro e autóctone, original. A hipótese de trabalho é a de que esses teóricos fazem parte do grupo de pensadores brasileiros que fundam um pensamento original, autóctone no Brasil a partir do início do século XX, mostrando em Manoel Bomfim a antecipação de pontos que seriam refletidos a partir da década de 1930 por diversos pensadores (tais como a crítica ao imperialismo dos EUA e a defesa do desenvolvimento industrial para superar a dependência) e, em Celso Furtado a inovação do debate sobre o subdesenvolvimento, tanto no período em que atuou na CEPAL (1949-1957) quanto naquele em que atuou na SUDENE (1959-1964).

\section{O pensamento de Manoel Bomfim}

Na extensa obra de Bomfim, destacamos como objeto de estudo aquelas dedicadas a uma interpretação (ensaística) do Brasil e América Latina, nas quais, acreditamos, o autor contribui de forma inédita com formulações político-sociais e históricas a partir das realidades brasileira e latina. Dentre elas: A América Latina: Males de Origem (escrito em 1903 quando estava em Paris e publicado em 1905 pela Editora Garnier). Neste livro, segundo Botelho (2009, p. 120), ele enfrenta a teoria do racismo científico e esboça reflexões sobre educação, racismo e a construção da nação Brasil que irá complementar na trilogia O Brasil na América: Caracterização da Formação Brasileira (escrito em 1925 e publicado em 1929), O Brasil na História: Deturpação das Tradições, Degradação Política (escrito em 1926 e editado em 1930), e, O Brasil Nação: Realidade da Soberania Brasileira (escrito em 1928, com posfácio de agosto de 1931, ano da publicação). Vale observar que a obra de Manoel Bomfim, a exceção do livro didático Através do Brasil, só volta a ser publicada na década de 1990 pela Topbooks. Através do Brasil (1910), escrito em parceria com o poeta Olavo Bilac, seu amigo, foi editado mais de sessenta vezes, sendo a última edição de 1962, circulando dessa forma, por cinco décadas nas escolas primarias. Para mais detalhes, ver Aguiar (2000). 
Bomfim coloca-se os pioneiros da crítica ao racismo científico que, baseado no determinismo biológico como modelo explicativo da sociedade, dividia a humanidade em raças superiores e inferiores, civilizados ou bárbaros. Obviamente, nós, os latinos, estávamos no segundo grupo. Para ele, os problemas do atraso e da desqualificação não podiam estar embasados na raça; outrossim, deveriam ser diagnosticados no parasitismo social do qual eram vítimas e da dominação externa (colonizadores) e interna (elites) a que estavam submetidos estes povos (da América Latina, em geral, e de modo específico, o Brasil). Intentava ver tais dilemas superados pela educação e orientação adequada destes sujeitos, que constituiriam então a Nação Brasileira, em particular; e de modo geral, os povos latino-americanos. Esta posição crítica, quase ácida ao posicionamento políticofilosófico de seus contemporâneos rendeu a Bomfim a pecha de utópico.

Outro aspecto do pensamento de Bomfim que podemos destacar é a sua defesa do desenvolvimento industrial como a melhor forma de superar a dependência (podendo nisso ser considerado um precursor do desenvolvimentismo), pois via as economias essencialmente agrícolas como sinônimas de economias colonizadas, podendo ser considerado nesse aspecto como um precursor de Caio Prado Júnior, tal como podemos observar no livro Formação do Brasil Contemporâneo (2000 [1942]).

Nessa reflexão, a busca da superação da dependência passava também por não aceitar o imperialismo, vendo no poderio norte americano uma ameaça à soberania dos países latino-americanos.

Em seu último livro - O Brasil Nação (1931), Bomfim já não acreditava na transformação social somente pela educação popular, e cada vez mais influenciado pelas ideias socialistas afirma que “(...) a democracia, voz da maioria, converteu-se em regime de exploração da maioria trabalhadora. [...]. É esta uma situação que só pode resolver revolucionariamente" (BOMFIM, 1996 [1931]: 566-567).

\section{A originalidade do pensamento de Celso Furtado}

Podemos observar a originalidade do pensamento de Celso Furtado tanto no período em que atuou na CEPAL (1949-1957) quanto no período em que esteve à frente da SUDENE (1959-1964). 
No período cepalino de Furtado destacamos as obras A Economia Brasileira (1954), Uma Economia Dependente (1956) e Perspectivas da Economia Brasileira (1958), que analisamos sucintamente nos parágrafos que seguem.

Em A Economia Brasileira (1954), é patente a preocupação em entender a economia brasileira no período em que é escrito o livro através do uso instrumental da história para compreender as características peculiares de uma economia subdesenvolvida como a brasileira. Esse livro se constitui na reunião das reflexões de Furtado em três frentes que ele trabalhava no período (como ele afirma em A Fantasia Organizada 1985):

I) Teoria do desenvolvimento: gênese histórica e mecanismos de acumulação.

II) Perspectiva histórica e problemas atuais da economia brasileira.

III) Crítica das ideias sobre desenvolvimento econômico.

Cabe destacar nesse livro a sua preocupação em mostrar que o sucesso da colonização no Brasil e o fracasso nos EUA se constituíram em raízes da situação de subdesenvolvimento que obstaculiza a construção da nação, mas também afirma o Brasil em suas potencialidades, dadas as semelhanças de recursos naturais e de tamanho de território entre esses dois países.

O livro Uma economia Dependente (1956) na verdade se constitui em partes dos capítulos 2, 3, 4 e 5 do livro de 1954.

O livro Perspectivas da Economia Brasileira (1958) se constitui em transcrição de conferências proferidas no ISEB em 1957, que giraram em torno de três temáticas:

I) Equacionamento do problema do desenvolvimento da economia brasileira na etapa vivida na década de 1950 (industrialização planejada a partir de 1956).

II) Análise de suas tendências fundamentais.

III) Tentativa de determinar os principais fatores que poderiam reduzir o ritmo desse desenvolvimento nos anos que se seguiriam.

Após sua saída da CEPAL em 1958, Furtado passa um período na Universidade de Cambridge (tal como vimos acima), local em que pesquisa e escreve o livro Formação econômica do Brasil - FEB (cuja primeira edição foi publicada em 1959), considerada pela maioria dos cientistas sociais e pelos estudiosos de seu pensamento como sua 
principal obra devido ao fato dela estar centrada na análise da evolução econômica do Brasil com a utilização do modelo keynesiano. Tal livro também se constitui numa ampliação da sua tese de doutorado de 1948 e do seu livro de 1954. Um outro ponto importante em $F E B$ se encontra no fato de que a preocupação com as disparidades regionais se torna cada vez mais realçada nas reflexões de Furtado, apesar dos avanços na industrialização. Ele defende a necessidade de políticas de desenvolvimento que almejassem o fim de tal situação, para que a nação continuasse seu processo de formação e construção.

Ao mesmo tempo em que elaborava o diagnóstico do subdesenvolvimento brasileiro para compreender tal obstáculo para a construção da nação, Furtado propunha a solução para a superação de tal situação através do planejamento democrático estatal, para promover o desenvolvimento econômico, tomando parte de um debate intenso no Brasil e no mundo sobre o planejamento e a industrialização para a superação do subdesenvolvimento (cf. FURTADO, 1985; VIEIRA, 2010). Podemos afirmar que no período em que Furtado participa da CEPAL, ocorre a predominância do técnico sobre o político, na visão do planejamento como elemento de superação do subdesenvolvimento e construção da nação.

No período em que atuou na SUDENE (1959-1964), Furtado atua pelo desenvolvimento do Nordeste como uma forma de diminuir as disparidades regionais no Brasil, tendo enfrentado muitas dificuldades para levar à frente seus projetos devido à forte oposição da direita e dos EUA. Além dessa atuação, ele continua sua reflexão sobre o desenvolvimento e o subdesenvolvimento, destacando-se os seguintes livros: A PréRevolução Brasileira (1962) e Dialética do Desenvolvimento (1964), que analisamos sucintamente nas linhas abaixo.

A Pré-Revolução Brasileira (1962) se constitui numa compilação de estudos, cuja preocupação é, segundo Furtado, esclarecer à juventude universitária brasileira sobre as grandes transformações pelas quais o Brasil passava naquele momento. Destacamos do livro uma primeira crítica ao modelo de desenvolvimento econômico adotado pelo país e que ele defendia: não houve modificação nas condições de vida de $75 \%$ da população brasileira, muito pelo contrário, houve uma crescente concentração social e geográfica de renda, além de ter levado a um aumento relativo da renda da terra. No plano políticoadministrativo, a ampliação e a diversificação das funções do Estado não foram 
acompanhadas das necessárias reformas de base do próprio Estado, o que colaborou para o enorme aumento do coeficiente de desperdício na ação administrativa pública. Dessa análise, podemos observar que o diagnóstico de Furtado acerca do desenvolvimento é dinâmico, significando para ele que durante a ação para superá-lo é possível reavaliá-la, reiterando sua defesa do planejamento democrático para o desenvolvimento econômico, dentro de sua defesa da socialdemocracia.

No livro Dialética do desenvolvimento (1964) destacamos o fato de que o autor observa os fatores dinâmicos da economia brasileira se debilitarem devido à conformação das forças políticas no período (e que apoiariam o golpe de 1964), que impedem a superação dos obstáculos estruturais do subdesenvolvimento.

Após o golpe de 1964, Furtado é cassado e parte para o exílio, onde continua suas reflexões sobre o subdesenvolvimento, mantendo sempre o caminho dinâmico do pensar esse fenômeno e as propostas de sua superação para que a construção da nação Brasil continue.

\section{Considerações finais}

Manoel Bomfim em suas principais obras, apresenta sua preocupação com a realidade nacional e latino-americana; a questão racial; a busca de uma concepção acerca do nacionalismo e a observação dos problemas da Latino-América - os conflitos entre seus países, o debate do socialismo e sua viabilidade, avançando para considerações políticas, econômicas e sociais que curiosamente, só encontrarão ênfase nas produções intelectuais de décadas depois. Estes fatos, somados, dão o tom da diferença e importância do pensamento bomfiniano neste período, e apontam para o que pensamos ser sua contribuição na formação de uma ciência social brasileira, autóctone, não importada nos seus vícios europeus ou norte-americanos, mas nascida da vivência social-histórica do autor, da realidade que matiza a sociedade de seu tempo. Salientada a importância do salto qualitativo de seu pensamento, nascido no seio do racismo científico, do cientificismo da época, para a crítica do mesmo e a proposição de novas reflexões na busca de soluções para os problemas da nação brasileira, e até da América Latina.

Celso Furtado, a partir de seu engajamento na CEPAL, faz um caminho original para diagnosticar o subdesenvolvimento brasileiro e propor alternativas à sua superação, 
elaborando uma reflexão que não faz um mero transplante das teorias originadas nos países centrais, mas sim adaptações à nossa realidade brasileira e latino-americana.

Por fim, podemos elencar como pontos em comum aos autores analisados a originalidade e a inovação dentro do contexto e do debate em que estão inseridos, além da crença na possibilidade de realizar a nação brasileira, comprovando nossa hipótese.

\section{Referências}

BOMFIM, Manoel. A América Latina: males de origem. Rio de Janeiro: Toopbooks, 1993 [1905].

BOMFIM, Manoel. O Brasil na América: caracterização da formação brasileira. $2^{\mathrm{a}}$ edição. Rio de Janeiro: Toopbooks, 1997 [1929].

BOMFIM, Manoel. O Brasil na história: deturpação das tradições, degradação política. $2^{a}$ edição. Rio de Janeiro: Toopbooks, 2013 [1930].

BOMFIM, Manoel. O Brasil Nação: realidade da soberania nacional. $2^{\mathrm{a}}$ edição. Rio de Janeiro: Toopbooks, 1996 [1931].

BOTELHO, André. Manoel Bomfim: um percurso da cidadania no Brasil. In.: BOTELHO, André; SCHWARTZ, Lilia Moritz. Um enigma chamado Brasil: 29 intérpretes e um país. São Paulo: Cia das Letras, 2009.

FURTADO, Celso. Economia Colonial no Brasil nos Séculos XVI e XVII. São Paulo: HUCITEC, ABPHE, 2001 (Tese de Doutorado, 1948).

FURTADO, Celso. A economia brasileira. Rio de Janeiro: Editora A Noite, 1954.

FURTADO, Celso. Uma economia dependente. Rio de Janeiro: Ministério da Educação e Cultura, 1956.

FURTADO, Celso. Perspectivas da economia brasileira. Rio de Janeiro: ISEB, 1958.

FURTADO, Celso. Formação econômica do Brasil. 34a edição. São Paulo: Companhia das Letras, 2007 [1959].

FURTADO, Celso. A pré-revolução brasileira. Rio de Janeiro: Fundo de Cultura, 1962. 
FURTADO, Celso. Dialética do desenvolvimento. Rio de Janeiro: Fundo de Cultura, 1964.

FURTADO, Celso. A fantasia organizada. Rio de Janeiro: Paz e Terra, 1985.

PRADO JR., Caio. Formação do Brasil contemporâneo: colônia. São Paulo: Brasiliense; Publifolha, 2000 [1942].

VIEIRA, Wilson. A construção da nação no pensamento de Celso Furtado. Campinas: IFCH-UNICAMP, 2010 (Tese, Doutorado em Sociologia). 